tion of the context will show what was intended. The error affected only that particular case, and not the principle involved; showing only that a higher coeflicient for the resistance of plane surfaces obtained in that instance, than 845 , which was therein deduced. The true coeficicient was $2 \cdot 347$.

But to prolong this discussion will be of little avail: the arguments, pro and con, are before those who take any interest in the subject. I shall, therefore, conclude what I have to say, by showing to Mr. Nystrom the fallacy of the argument on which he relies for proof-an argument on which he appears to have expended a vast number of figures and equations.

To demonstrate this point, we have only to examine the diagrams by which the argument is illustrated.

We there find that a fulcrum, which has always been supposed to be a point of support for the action of the power, in propelling a vessel as well as in moring any other resistance, is an imaginary point in the area of a paddle wheel, situated somewhere between the shaft and the immersed Hoat- the position of this point being determined merely by the ratio between the advance of the vessel and the slip. This is a very convenient (for the argument) and quite origmal method of viewing the lever. There is only one trifling circumstanee overlooked, which is, that the "fulcrum" moves over space in the same direction and with the same velocity as the resistance.

To those who are content with the old method of considering the lever, it is easier to suppose that the fulcrum is in the water; that this fulcrum recedes a certain proportion of the whole movement due to the power; and that the resistance is moved over a space equal to the difference between these two spaces: in other words, that the arm of a paddle wheel is to be judged of precisely in the same manner as the arm of a locomo. tive driving wheel.

For the Jomal of the Franklin Institute.

\title{
On the Comparative Value of Anthracite and Bituminous Coals for the purpose of Generating Steam.
}

Congress has recently called on the Secretary of the Navy for the report of the Engineer in Chief, Charles B. Stuart, Esq., on the comparative value of the two different kinds of coal for the purpose of generating stearn. Some years since a large number of experiments were made by Professor Walter R. Johnson, from samples of coal furnished by miners, all of which were published by authority of Congress; and in consequence of the result of those experiments, the naval steamers have been supplied with Cumberland coal, very much to their injury and expense.

The only true test of the comparative value of coal is to take the two kinds as they are delivered at your ship, stowed in the bunkers, and brought out at your boilers ready for use. The antbracite will undergo all this without change, while the Cumberland, from its friable nature, becomes reduced almost to a powder. 
The experiments of Mr. Stuart are from two lots of coal delivered at the New York Nary Yard, and the contents of the large stone dock at that station have been several times pumped out with each kind. The result has not yet been made public, but it is understood that the anthracite is about 50 per cent. cheaper than the bituminous, the difference in cost of each per ton being considered.

Many of our naval engineers have for several years past been strongly in favor of anthracite coal, owing to the very great trouble of getting any Cumberland suitable for steaming. The steamer Fulton is fitted for anthracite; the Saranac recently took in 150 tons of it at San Juan de Nicaragua, and her engineer prefers it to bituminous; the Mississippi now has 300 tons in her bunkers, for her next cruise; and, in fact, the general feeling is in its favor, and this feeling is in a great measure caused by the want of mechanical strength in the Cumberland coal, to withstand the necessary handling before it reaches the furnaces. In this respect the Cumberland is inferior to most coals of that class, particularly the English. The City of Glasgow burns Cardiff coal on her trips to this port, and is enabled without difficulty to carry a fair pressure of steam. On her return, she burns Cumberland, and cannot make steam sufficient even with an increased supply of fuel.

In addition to the economic value of anthracite coal, it is entirely free from all danger of spontaneous combustion.

$B$.

For the Journal of the Franklin Institute.

On Ericsson's Caloric Engine.

Messrs. Hogg \& Delamater, of New York, are constructing for and under the superintendence of Captain Ericsson, a pair of very large caloric engines, intended for a vessel of about 1900 tons, and every possible exertion is being made to have her ready for sea in September. It is not my purpose to discuss the merits of this engine at the present time, deeming it sufficient to say, that after many years of active exertions, Captain E. has at last perfected to his own satisfaction and that of his friends, his caloric engine. It has been fully secured by patent in this country and in Europe. A model engine of 60 horse power has been in operation at the works of Messrs. H. \& D. for months past, and it has been repeatedly tested to their entire satisfaction.

The machinery for this vessel will be a pair of engines, one abaft the other, in line with the keel of the ship. Each engine has two cylinders (single acting) of the diameter of 14 feet, with 6 feet length of stroke. 'To each engine there is one beam, and the connecting rods from both engines take hold of the same crank-pin, but from the position of the engines, both are not on the centre at the same time. There are two air pumps to each engine, for forcing the proper quantity of air into the receiver; their diameter is $137 \frac{1}{2}$ inches, and stroke same as that of the cylinders, directly over which they are secured. The pistons of the two are connected together by several rods, and it is from the lower side of the air pump piston that the power is communicated through the beams to 